\title{
Spectroscopy and Photodissociation of Dimethylzinc in Solid Argon. 2. FTIR Detection/ ArF Laser Photolysis
}

\author{
Veronica A. Bracken, ${ }^{\dagger}$ Nicole Legay-Sommaire, ${ }^{\ddagger}$ and John G. McCaffrey ${ }^{*}{ }^{\dagger}$ \\ Department of Chemistry, National University of Ireland, Maynooth, Co. Kildare, Ireland, and Laboratoire de \\ Photophysique Moléculaire du CNRS, Bâtiment 213, Université de Paris-Sud, 91405 Orsay Cedex, France
}

Received: July 14, 1997; In Final Form: October 15, $1997^{\otimes}$

\begin{abstract}
The IR spectroscopy of matrix-isolated DMZ is presented as a precursor for the analysis of DMZ photochemistry in the solid rare gases. In agreement with gas-phase work, the present study reassigns the band observed at $1309.2 \mathrm{~cm}^{-1}$, currently assigned in the matrix literature to the bending mode of the impurity methane, to the $v_{10}+v_{14}$ band combination mode of DMZ. From a combination of IR absorption and UV luminescence studies, atomic zinc and a pair of methyl radicals $\left(\mathrm{Zn}+2 \mathrm{CH}_{3}\right)$ are identified as the photochemical products formed with ArF excimer laser photolysis. A concerted dissociation pathway of DMZ in solid Ar is considered to be the only mechanism leading to the production of methyl radicals in the vicinity of ground-state atomic zinc. The lack of observation of the methylzinc $\left(\mathrm{CH}_{3} \mathrm{Zn}\right)$ and methyl radicals as products is explained in terms of the rapid geminate recombination of these radicals in the matrix cage, which in turn explains the poor efficiency of DMZ dissociation in the solid. Evidence exists for the formation of secondary products with ArF photolysis, namely, the production of ethylzinc hydride and acetylene. It is proposed that the former arises from the excited-state insertion of atomic zinc into the $\mathrm{C}-\mathrm{H}$ bonds of the small amounts of ethane arising from the recombination of the methyl radicals. Acetylene is a product of ArF dissociation of ethylene which results from recombination of hot methyl radicals.
\end{abstract}

\section{Introduction}

Although one of the earliest polyatomic molecules whose vibrational motion was examined with IR spectroscopy, ${ }^{1}$ analysis of the rotational structure ${ }^{2}$ of the vibrational bands of DMZ is still lacking due to the spectral congestion occurring as a result of the free internal rotation of the methyl groups. The IR spectroscopy of matrix-isolated DMZ has been analyzed in one previous study, viz., a low-resolution study of Grinter and coworkers, which confirmed most of the earlier gas-phase assignments $^{3}$ but reversed the existing assignment of the band at $1309.2 \mathrm{~cm}^{-1}$ from the combination $v_{10}+v_{14}$ mode of DMZ to the $v_{4}$ bending mode of methane. Purification procedures followed in the present work allow for the misassignment of the matrix work to be corrected.

From a comparison of the IR matrix spectra of stable hydrocarbons, the assignments of the photochemical products of DMZ with ArF photolysis are made. Annealing studies are used to examine the stability of the photochemical products. The structure of this paper is as follows. Initially the experimental details of the matrix IR setups in Maynooth and Orsay are presented followed by an outline of the DMZ/Ar concentration studies. This is followed by a presentation of the results observed with ArF photolysis of DMZ and upon annealing these photolyzed samples. To assist in the assignments of the photochemical products, IR absorbance spectra of the hydrocarbons ethane, ethylene, and acetylene isolated in Ar were recorded. Once definite assignments of these photochemical products were made in the annealed samples, the identification of the bands associated with the remaining photochemical products was embarked upon.

* To whom correspondence should be addressed.

† National University of Ireland.

‡ Université de Paris-Sud.

\& Abstract published in Advance ACS Abstracts, December 1, 1997.

\section{Experimental Section}

A. Maynooth. Thin film DMZ/Ar samples were produced in Maynooth by the condensation at $12 \mathrm{~K}$ of gaseous mixtures of DMZ in Ar, prepared in a ultrahigh vacuum gas-handling system (GHS) evacuated by a Balzers TPU180H turbomolecular pump, onto a CsI window mounted on the cold tip of an APD Cryogenics Displex closed-cycle CSW 202 refrigerator system. Well-defined DMZ/Ar gas mixtures were prepared in the GHS having dilution ratios in the range $1 / 100$ to $1 / 5000$. Two Tylan General Baratron capacitance manometers spanning two pressure ranges of $0-10$ and $0-1000$ Torr, Model CDLD 31 and CDLG 11 , respectively, were used to monitor the amount of gas admitted to the system. Prior to cooldown, a vacuum of $10^{-7}$ mBar was attained in the sample chamber using an Edwards EO2K oil vapor diffusion pump backed by an Edwards E2M2 mechanical pump. After displex cooldown and with a filled liquid nitrogen cold trap, vacuum outside the sensitivity range of the Alcatel FA111 penning gauge was reached.

Argon gas, supplied by Linde Technische Gase, of 99.999\% purity was used without further purification. DMZ of 95\% purity was obtained from Alpha Gaz, Johnson Matthey Co., and was subjected in the GHS to freeze-pump-thaw (FPT) cycles with liquid nitrogen before the argon gas was added in excess. This was necessary due to the extreme moisture sensitivity of DMZ. With the small amounts of DMZ present in the highdilution mixtures utilized in the present study, significant decomposition of DMZ occurred, even under the ultrahigh vacuum conditions of the GHS, with the production of methane and zinc oxide. Consequently, the gas-handling system was passivated with DMZ, the unreacted DMZ frozen out at liquid nitrogen temperature, and the residual methane gas evacuated from the gas-handling system. This FPT procedure was usually repeated 3 or 4 times to avoid methane contamination as established in the present FTIR study of DMZ/Ar. 
Thin film samples were formed at $12 \mathrm{~K}$ by continuous sprayon of the DMZ/Ar mixtures at flow rates of $8-10 \mathrm{mmol} / \mathrm{h}$ onto a CsI window. A Granville-Phillips (Model 203) variable leak valve was used to control the flow rate during the 25-30 min deposition periods used in sample formation. Spectra, in the $400-3500 \mathrm{~cm}^{-1}$ range, were recorded at $12 \mathrm{~K}$ at a resolution of $0.125 \mathrm{~cm}^{-1}$ using a Nicolet Magna 550 FTIR spectrometer equipped with a DTGS detector and a CsI beam splitter. Sample annealing was achieved with a Scientific Instruments 9600-1 temperature controller and monitored by an SI-410A silicon diode. Photochemical activity in the DMZ/Ar system was examined in Maynooth with an Oriel $1000 \mathrm{~W}$ high-pressure Xe-arc lamp, fitted with UV-enhanced fused silica optics, and using an ARC 200-W-1D band-pass filter.

B. Orsay. Details of the experimental apparatus located at Orsay have been described in earlier communications by LegaySommaire et al. ${ }^{4}$ The apparatus is similar to the Maynooth experiment described above with the following exceptions. Samples were condensed on a CsBr window mounted onto the cold tip of a 4-L liquid helium SMC cryostat. FTIR spectra were recorded on a Bruker IFS $120 \mathrm{HR}$ spectrometer at a resolution of $0.1 \mathrm{~cm}^{-1}$ over a spectral range of $530-3500 \mathrm{~cm}^{-1}$. Samples were irradiated at 193 and $248 \mathrm{~nm}$ using $\mathrm{ArF}$ and $\mathrm{KrF}$ fillings, respectively, of a Sopra excimer laser.

\section{Results}

A. Concentration Study. A concentration study was initially conducted in order to identify the optimal conditions for the isolation of DMZ monomer in argon for deposition at $12 \mathrm{~K}$, the temperature subsequently used in all the photochemical studies. In Figure 1, the vibrational absorptions of the fundamental $\mathrm{C}-\mathrm{H}$ stretch modes of the methyl groups are shown for annealed DMZ/Ar samples which were deposited with the same flow rate but with the specified dilution ratios. With the exception of the uppermost trace, recorded for a sample deposited at $20 \mathrm{~K}$, all other samples were deposited at $12 \mathrm{~K}$. The weaker red sidebands indicated by the asterisks are seen to be dependent on the concentration of DMZ for the DMZ/Ar dilution ratios indicated in Figure 1. Sample mixtures deposited at 12 and $20 \mathrm{~K}$ having a dilution ratio of 1/100 demonstrated the most pronounced differences. No differences were obvious for mixtures having a dilution ratio greater than 1/1000, indicating that the isolation of monomer DMZ was achieved. Thus, the red sidebands were attributed to dimer DMZ for dilutions less than $1 / 1000$, while the remnants of sidebands present even in the 1/5000 sample, exhibiting the same relative intensity as the $1 / 1000$ sample but a poorer signal-to-noise ratio, were attributed to a minor site of isolation of monomer DMZ in solid Ar.

Assignments of DMZ/Ar Vibrational Bands. The vibrational bands of DMZ observed in solid argon are consistent with a recent gas-phase study of Coats et al. ${ }^{5}$ In the spectral region shown in the top panel of Figure 2, three vibrational transitions are observed pertaining to the different $\mathrm{C}-\mathrm{H}$ stretches of the methyl groups of DMZ. The two perpendicular $v_{8}$ and $v_{12}$ bands at 2973.5 and $2850.6 \mathrm{~cm}^{-1}$, respectively, exhibit noticeably larger line widths than the parallel $v_{5}$ band at $2921.8 \mathrm{~cm}^{-1}$. In the middle panel of Figure 2, the parallel $v_{6}$ fundamental band is located at $1181.9 \mathrm{~cm}^{-1}$ and the much weaker band at 1309.2 $\mathrm{cm}^{-1}$ is assigned to the combination $v_{10}+v_{14}$ band. A comparison of the $v_{10}+v_{14}$ band for two DMZ/Ar samples having the same concentration, but one of which is slightly contaminated with methane as a result of DMZ decomposition prior to deposition, is shown on an expanded vertical scale in the middle panel in Figure 2. The peak marked with an asterisk

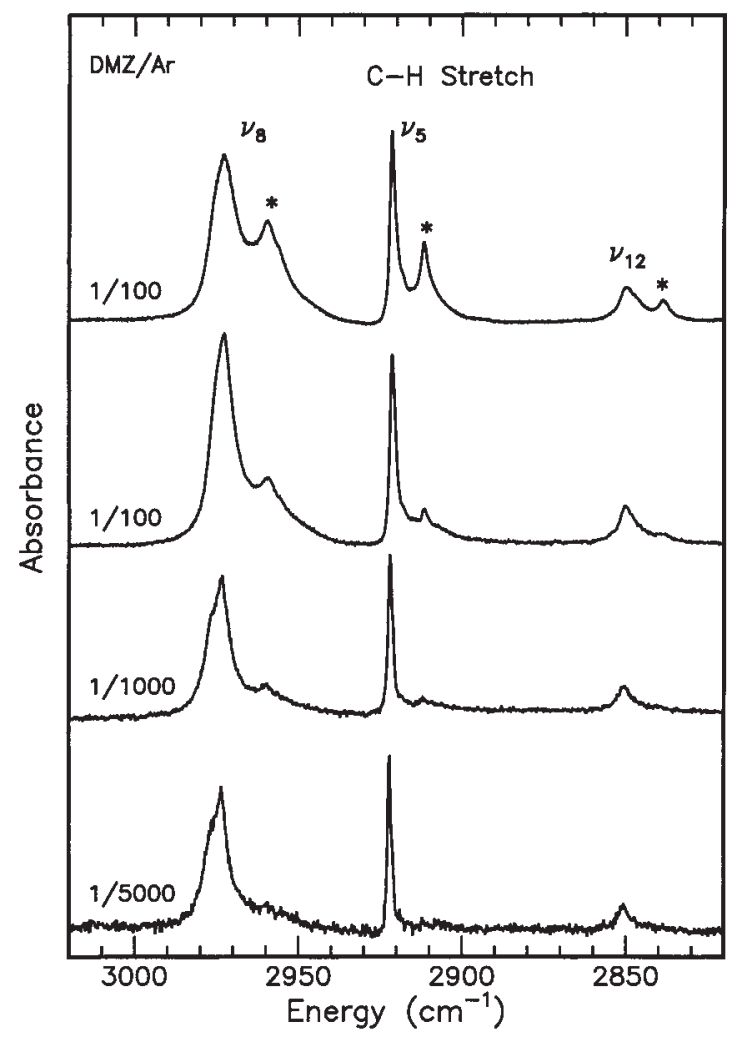

Figure 1. Comparison of the $\mathrm{C}-\mathrm{H}$ stretch modes of $\mathrm{DMZ} / \mathrm{Ar}$ samples having the specified dilution ratios of $1 / 100,1 / 1000$, and $1 / 5000$, recorded at $12 \mathrm{~K}$ and an instrumental resolution of $0.25 \mathrm{~cm}^{-1}$. All samples were formed at $12 \mathrm{~K}$ with the exception of the top trace which was deposited at $20 \mathrm{~K}$. For dilution ratios of $1 / 100$ and $1 / 500$, the weaker red sidebands indicated by asterisks are assigned to dimer DMZ, while the intense bands are assigned to monomer DMZ. For samples of dilutions of $1 / 1000$ to $1 / 5000$, the weak sideband is assigned to a minor site of isolation of monomer DMZ.

pertains to the $v_{4}$ mode absorption of methane at $1304.6 \mathrm{~cm}^{-1}$. The $v_{10}+v_{14}$ combination band of DMZ was masked by this strong methane band in a previous low-resolution matrix study of Bochmann et al. ${ }^{6}$ because of extensive decomposition of DMZ.

In the bottom panel of Figure 2, the parallel $v_{7}$ band at 619.7 $\mathrm{cm}^{-1}$ corresponding to the $\mathrm{C}-\mathrm{Zn}-\mathrm{C}$ asymmetric stretch exhibits a 3-fold splitting in which the components have relative intensities of 5:3:2 arising from the 48.89, 27.81, and $18.57 \%$ relative abundances of the naturally occurring isotopes of atomic zinc: ${ }^{64} \mathrm{Zn}$, ${ }^{66} \mathrm{Zn}$, and ${ }^{68} \mathrm{Zn}$, respectively. The splitting between the isotopic components is 2.89 and $2.73 \mathrm{~cm}^{-1}$. The perpendicular $v_{10}$ mode is observed as a broad band centered at 698.7 $\mathrm{cm}^{-1}$.

The weaker, mostly combination vibrational transitions of DMZ in solid argon are shown in Figure 3. The triplet feature at $1792.5 \mathrm{~cm}^{-1}$ displays the same relative intensities as the $v_{7}$ band, shown in Figure 2, and is assigned to the $v_{2}+v_{7}$ combination band but exhibiting slightly larger splittings of 3.13 and $3.08 \mathrm{~cm}^{-1}$ than the $v_{7}$ band. In the middle panel of Figure 3 , the band centered at $1700.0 \mathrm{~cm}^{-1}$ is assigned to the parallel $v_{3}+v_{6}$ band. In the bottom panel, the $v_{10}+v_{14}$ parallel band mentioned previously is shown for the sake of comparison. A broad band exhibiting a sharp feature at $1437.8 \mathrm{~cm}^{-1}$ is assigned to the perpendicular $v_{9}$ band of the $\mathrm{CH}_{3}$ deformation mode of DMZ. A summary of the observed fundamental and combination infrared active bands of matrix-isolated DMZ in solid argon is presented in Table 1 as well as the assignments and gasphase band origins identified by Coats et al. ${ }^{5}$ From an examination of the differences existing between the gas-phase band 

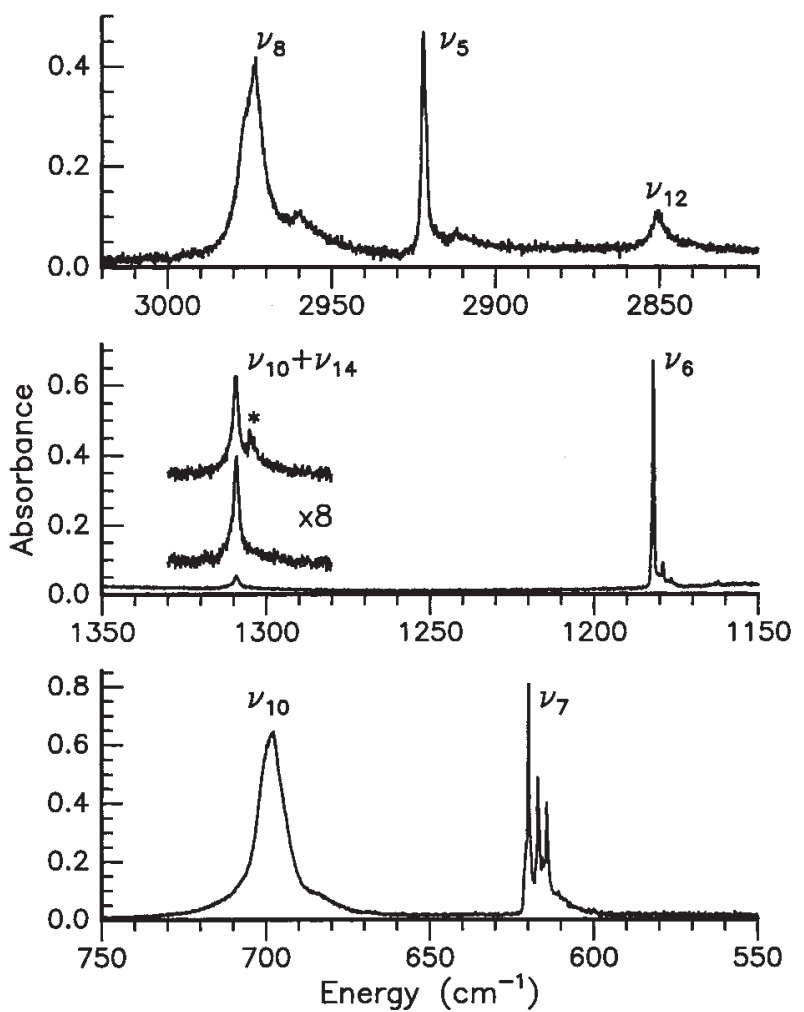

Figure 2. Most intense vibrational transitions of the DMZ/Ar sample having a dilution ratio of 1/1000 recorded with an instrument resolution of $0.25 \mathrm{~cm}^{-1}$ at $12 \mathrm{~K}$. Assignments of the vibrational transitions were made from the gas-phase data of Coats et al. In the middle panel, the $v_{10}+v_{14}$ band is shown in an exaggerated fashion. The uppermost exaggerated spectra display an additional peak, indicated by the asterisk, due to contamination by methane.

origins and band maxima in Ar, it can be stated that only minor matrix shifts exist on the vibrational transitions of DMZ in solid Ar.

B. Photochemistry of DMZ/Ar. Freshly Photolyzed. No photochemical products were observed when freshly deposited DMZ/Ar samples were irradiated either with the $1000 \mathrm{~W}$ output of a high-pressure Xe-arc lamp having an output down to 220 $\mathrm{nm}$ or a $\mathrm{KrF}$ excimer laser at $248 \mathrm{~nm}$. The reason for this lack of photochemical activity can be traced back to the large blue shifts present, as described in the previous paper, ${ }^{15}$ on both the $\mathrm{B} \leftarrow \mathrm{X}$ and $\mathrm{A} \leftarrow \mathrm{X}$ transitions of $\mathrm{DMZ}$ in the matrix. In contrast, the photochemical activity of matrix-isolated DMZ was observed as a result of ArF laser excitation at $193 \mathrm{~nm}$.

"Difference" absorption spectra ${ }^{7}$ were used in the FTIR work to detect the growth of photochemical products produced at 12 $\mathrm{K}$. The spectra recorded after a 73-min photolysis with the ArF laser operating at a repetition rate of $3 \mathrm{~Hz}$ are presented in the bottom traces of Figures 4-6 for those spectral regions in which changes were observed. The most intense bands produced are attributed to the simple hydrocarbon products ethylene (E) and ethane (A). Ill-defined absorption bands of ethane at 820, 1374, and $1466 \mathrm{~cm}^{-1}$ were observed together with the bands located at 948 and $1438 \mathrm{~cm}^{-1}$ associated with the $v_{7}$ and $v_{12}$ modes, respectively, of ethylene. Only the major absorptions of these hydrocarbons were observed due to the small amounts of the species formed during photolysis. In addition, the difference spectra revealed new weak bands at 545.8 and $579 \mathrm{~cm}^{-1}$. A complex feature absorbing at $635 \mathrm{~cm}^{-1}$ and a sharp feature centered at $730.4 \mathrm{~cm}^{-1}$ with a broad band at $735 \mathrm{~cm}^{-1}$ were also observed. Higher frequency features were observed at 827 and $829 \mathrm{~cm}^{-1}$ and as well as the pair of bands at 1869 and $1878 \mathrm{~cm}^{-1}$ in which each pair exhibited the same relative
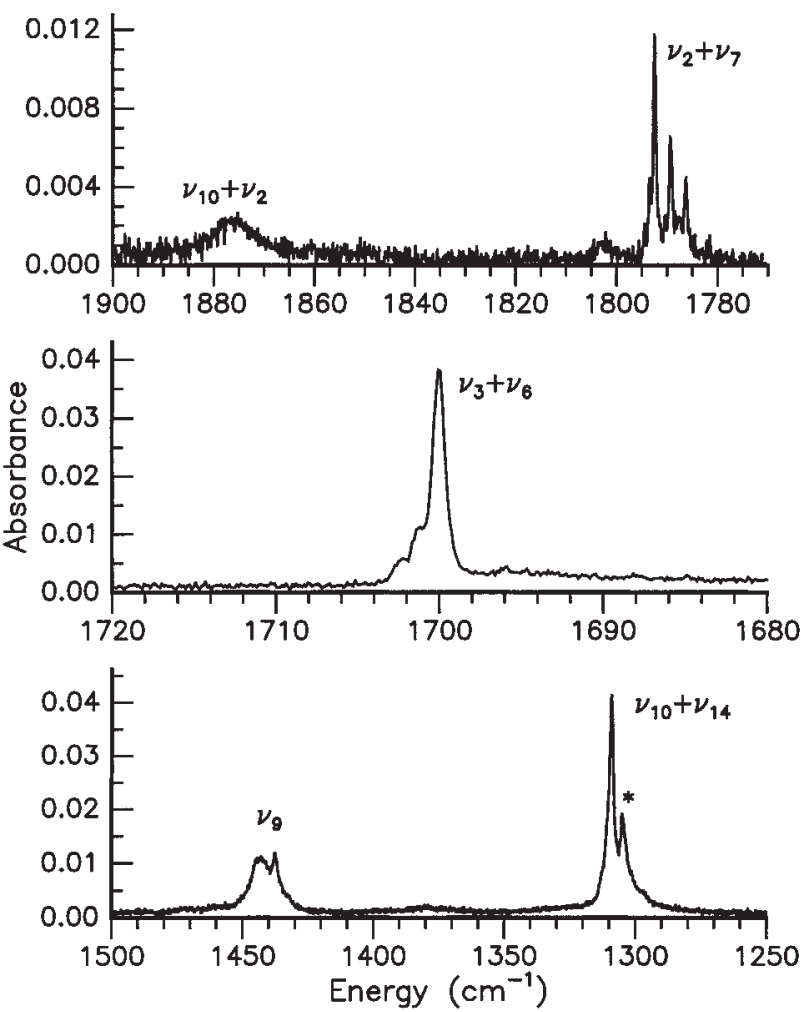

Figure 3. Weaker vibrational transitions of a 1/1000 DMZ/Ar sample recorded with an instrument resolution of $0.25 \mathrm{~cm}^{-1}$ at $12 \mathrm{~K}$. All bands are combination bands with the exception of the $v_{9}$ band at 1437.7 $\mathrm{cm}^{-1}$. The asterisk indicates the same methane absorption shown in the middle panel of Figure 2.

TABLE 1: Comparison of the Positions of the Band Origins Observed in the Gas Phase ${ }^{5}$ and the Band Maxima Observed at $12 \mathrm{~K}$ in the Present Matrix Study for the Infrared Active Bands of Dimethylzinc $^{a}$

\begin{tabular}{lccc}
\hline $\begin{array}{c}\text { mode and } \\
\text { symmetry }\end{array}$ & $\begin{array}{c}\text { gas-phase } \\
v_{0}, \mathrm{~cm}^{-1}\end{array}$ & $\begin{array}{c}\text { matrix } \\
\nu_{\max }, \mathrm{cm}^{-1}\end{array}$ & $\begin{array}{c}\text { matrix shift, } \\
\mathrm{cm}^{-1}\end{array}$ \\
\hline$v_{8}(\perp)$ & 2965.8 & 2973.5 & +7.7 \\
$v_{5}(\mathrm{II})$ & 2913.4 & 2921.8 & +8.4 \\
$v_{12}(\perp)$ & 2842.0 & 2850.6 & +8.6 \\
$v_{10}+v_{2}(\perp)$ & 1887.0 & 1875.2 & -11.8 \\
$v_{2}+v_{7}(\mathrm{II})$ & $1794.0^{b}$ & $1792.5^{b}$ & -1.5 \\
$v_{3}+v_{6}(\mathrm{II})$ & 1699.2 & 1700.0 & +0.8 \\
$v_{9}(\perp)$ & 1440.0 & 1437.8 & -2.2 \\
$v_{10}+v_{14}(\mathrm{II})$ & 1303.5 & 1309.2 & +5.7 \\
$v_{6}(\mathrm{II})$ & 1186.3 & 1181.9 & -4.4 \\
$v_{10}(\perp)$ & 704.0 & 698.7 & -5.3 \\
$v_{7}(\mathrm{II})$ & $617.5^{b}$ & $619.7^{b}$ & +2.2
\end{tabular}

a An Ar matrix was used as host having a DMZ/Ar dilution ratio of 1/1000. ${ }^{b}$ Values quoted pertain to the ${ }^{64} \mathrm{Zn}$ isotopomer of DMZ.

intensities but splittings of different magnitude. The remaining unidentified product bands were a distinct strong absorption centered at $1378 \mathrm{~cm}^{-1}$ and a sharp weaker feature absorbing at $960 \mathrm{~cm}^{-1}$.

Annealed. The effects of annealing the photolyzed DMZ/ Ar sample to $33 \mathrm{~K}$ are shown in the middle traces of Figures 4-6. With the exception of the band at $730.4 \mathrm{~cm}^{-1}$, annealing produced a narrowing of all the absorption bands but an enhancement in the intensity of the ethane bands. To assist in the assignments of the photochemical products, IR absorbance spectra of the hydrocarbons ethane, ethylene, and acetylene isolated in annealed Ar samples are shown inverted for the purpose of presentation on the tops of Figures 4-6 recorded at $12 \mathrm{~K}$ for $1 / 1000$ dilution samples.

In the $3000-2880 \mathrm{~cm}^{-1}$ region, depicted in the left panel of Figure 4, bands attributable to ethane were observed to grow 

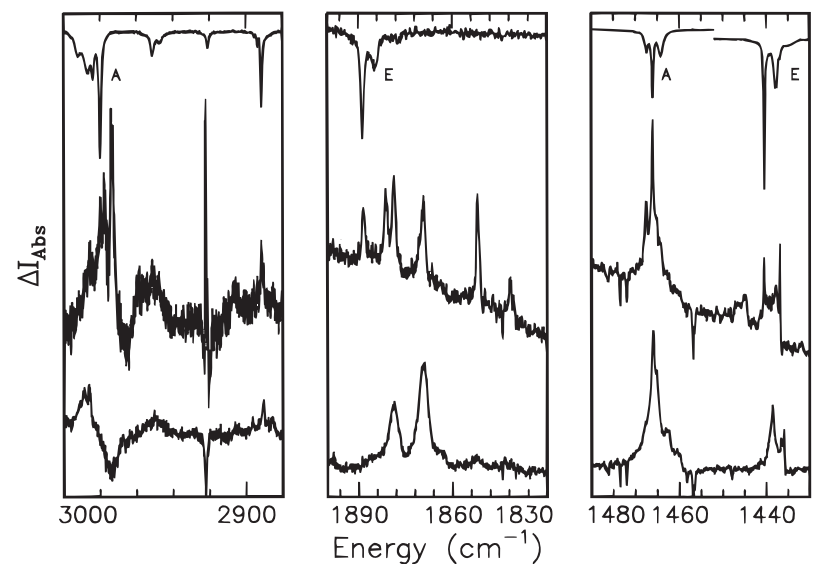

Figure 4. Difference spectra recorded at $12 \mathrm{~K}$ with a resolution of $0.1 \mathrm{~cm}^{-1}$ for three different spectral regions in the range of 3000$1430 \mathrm{~cm}^{-1}$ in which photochemical products were observed. The lower traces in all the panels correspond to a fresh DMZ/Ar sample photolyzed with the ArF laser, while the middle trace corresponds to the same photolyzed sample but annealed to $33 \mathrm{~K}$ for $25 \mathrm{~min}$. The upper traces correspond to inverted absorption bands of ethane (A), ethylene (E), and acetylene $(\mathrm{Y})$ which are shown to facilitate product identification.
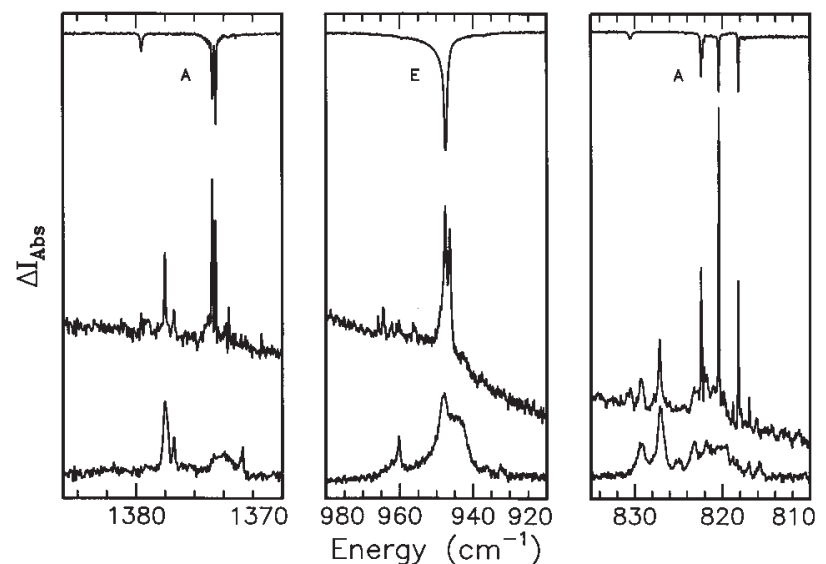

Figure 5. As in Figure 4.
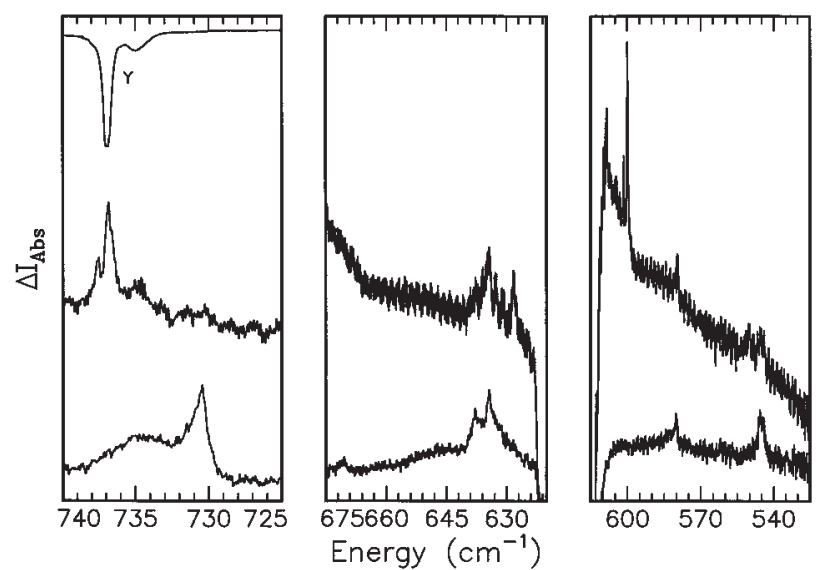

Figure 6. As in Figure 4

in intensity upon annealing. A corresponding growth of the $v_{6}$ and the $v_{9}$ modes of ethane at 1374.8 and $820.4 \mathrm{~cm}^{-1}$ were observed as shown in the left and right panels, respectively, of Figure 5. In the $1900-1830 \mathrm{~cm}^{-1}$ spectral range of Figure 4, a slight decrease in the intensity and a narrowing of the 1869.3 $\mathrm{cm}^{-1}$ band was observed after annealing. The feature at 1878 $\mathrm{cm}^{-1}$ resulted in a doublet feature of unequal intensities at 1878.2 and $1881.3 \mathrm{~cm}^{-1}$ as well as a third weaker band at 1888.6 $\mathrm{cm}^{-1}$. This weaker band at $1888.6 \mathrm{~cm}^{-1}$ produced as a result of annealing is readily assigned to the $v_{7}+v_{8}$ mode of ethylene shown in the top trace of Figure 4. Satellite bands at 1841.9, 1852.1, and $1870.8 \mathrm{~cm}^{-1}$ emerged during the stepwise annealing from ill-defined features present in the freshly photolyzed samples.

The bands centered at 1437.7 and $1466.1 \mathrm{~cm}^{-1}$ in Figure 4 which became more spectrally resolved after annealing, were assigned to the $v_{12}$ and $v_{8}$ modes of ethylene and ethane, respectively, but both are clearly overlapped by absorptions of other species as a comparison of the middle and upper traces reveals. Similar behavior was exhibited by the $v_{7}$ absorption of ethylene at $947.6 \mathrm{~cm}^{-1}$ as shown in the middle panel of Figure 5. Of particular importance in the $740-725 \mathrm{~cm}^{-1}$ range of Figure 6 is the presence of a feature centered at $730.4 \mathrm{~cm}^{-1}$ in the freshly photolyzed samples. This band disappeared completely when the samples were annealed. The broad band centered at $735 \mathrm{~cm}^{-1}$ which shifts blue to $736.8 \mathrm{~cm}^{-1}$ when annealed is assigned to the asymmetric bending $v_{5}$ mode of acetylene.

Secondary Photochemistry. The intense higher frequency bands at 1852.1, 1869.3, 1878.7, and $1881.3 \mathrm{~cm}^{-1}$ are assigned to various $\mathrm{Zn}-\mathrm{H}$ stretching modes of $\mathrm{C}_{2} \mathrm{H}_{5} \mathrm{ZnH}$ based on the similarity of the corresponding $\mathrm{Zn}-\mathrm{H}$ mode of $\mathrm{CH}_{3} \mathrm{ZnH}$ reported by Greene et $a .^{8}$ at $1866.1 \mathrm{~cm}^{-1}$. The location of the band at $545.8 \mathrm{~cm}^{-1}$ assigned to the $\mathrm{Zn}-\mathrm{C}$ stretching mode of $\mathrm{C}_{2} \mathrm{H}_{5} \mathrm{ZnH}$ also demonstrates similarity with the $\mathrm{Zn}-\mathrm{C}$ stretching mode of $\mathrm{CH}_{3} \mathrm{ZnH}$ at $565.1 \mathrm{~cm}^{-1}$. Based on the analogy established between $\mathrm{CH}_{3} \mathrm{ZnH}$ and $\mathrm{C}_{2} \mathrm{H}_{5} \mathrm{ZnH}$ molecules, the corresponding symmetric deformation mode of $\mathrm{CH}_{3}$ of $\mathrm{CH}_{3}-$ $\mathrm{ZnH}$ in $\mathrm{C}_{2} \mathrm{H}_{5} \mathrm{ZnH}$ needs to be identified. The study performed by Mink and Goggin ${ }^{9}$ has indicated that the $\mathrm{CH}_{2}$ wagging mode of ethylmercury halides are akin to the symmetric deformation of $\mathrm{CH}_{3}$ in methyl mercury halides. In the ethylmercury halide systems, the $\mathrm{CH}_{2}$ wagging mode exhibits a strong halide dependence; for example, the absorption located at $1178 \mathrm{~cm}^{-1}$ for $\mathrm{C}_{2} \mathrm{H}_{5} \mathrm{HgI}$ shifts to $1189 \mathrm{~cm}^{-1}$ for $\mathrm{C}_{2} \mathrm{H}_{5} \mathrm{HgBr}$. In $\mathrm{CH}_{3} \mathrm{HgX}$ systems, the symmetric $\mathrm{CH}_{3}$ deformation mode exhibits similar sensitivity to the halide atom in the molecule. Thus, the two prominent bands at 827 and $829 \mathrm{~cm}^{-1}$ in the right panel of Figure 5, which grow in unison with the pair of bands at 1878.2 and $1881.3 \mathrm{~cm}^{-1}$, are assigned to the $\mathrm{CH}_{2}$ wagging mode of $\mathrm{C}_{2} \mathrm{H}_{5} \mathrm{ZnH}$.

The features observed at $1378 \mathrm{~cm}^{-1}$ in a freshly photolyzed $\mathrm{DMZ} / \mathrm{Ar}$ sample in the left panel of Figure 5 sharpen upon annealing and are assigned to a symmetric deformation mode of the methyl group of $\mathrm{C}_{2} \mathrm{H}_{5} \mathrm{ZnH}$. This assignment was made in conjunction with the IR assignments of Mink and Goggin ${ }^{9}$ on ethylmercury(II) halides in solution whereby a deformation mode of $\mathrm{CH}_{3}$ was observed at $1379 \mathrm{~cm}^{-1}$. In their work, a $\mathrm{C}-\mathrm{C}$ absorption was observed at $967 \mathrm{~cm}^{-1}$; accordingly, the sharp features at $960 \mathrm{~cm}^{-1}$, in the middle panel of Figure 5 which endures loss in intensity but is accompanied by the growth of multiple weak bands at $960.3,964.5$, and $965.8 \mathrm{~cm}^{-1}$ when annealed, are assigned to the $\mathrm{C}-\mathrm{C}$ stretch of $\mathrm{C}_{2} \mathrm{H}_{5} \mathrm{ZnH}$. The unassigned sharp feature at $1436.9 \mathrm{~cm}^{-1}$ of Figure 4 is assigned to the $\mathrm{CH}_{2}$ bending mode of $\mathrm{C}_{2} \mathrm{H}_{5} \mathrm{ZnH}$. A pronounced intense shoulder located at $1465.4 \mathrm{~cm}^{-1}$ which is not characteristic of the $v_{8}$ mode of ethane was assigned to the methyl asymmetric deformation mode of $\mathrm{C}_{2} \mathrm{H}_{5} \mathrm{ZnH}$. Several bands in the 3000$2880 \mathrm{~cm}^{-1}$ region were also assigned to various $\mathrm{C}-\mathrm{H}$ stretches of $\mathrm{C}_{2} \mathrm{H}_{5} \mathrm{ZnH}$ as indicated in Table 2.

In Figure 6, the weak bands observed at 545.8 and 579.6 $\mathrm{cm}^{-1}$ in freshly photolyzed samples in the $535-610 \mathrm{~cm}^{-1}$ range remained after annealing but were accompanied by new bands at 550.7, 599.9, and $608.4 \mathrm{~cm}^{-1}$. The sharp feature at 545.8 $\mathrm{cm}^{-1}$ already assigned to the $\mathrm{Zn}-\mathrm{C}$ stretching mode of $\mathrm{C}_{2} \mathrm{H}_{5}-$ 
TABLE 2: Positions of the Photochemical Products in the Difference Spectra Recorded at $12 \mathrm{~K}$ with a Resolution of $0.1 \mathrm{~cm}^{-1}$ of a DMZ/Ar Sample Having a Dilution Ratio of 1/1000 after Irradiation Using an ArF Laser at $193 \mathrm{~nm}$ and Annealed to $33 \mathrm{~K}$

\begin{tabular}{|c|c|c|}
\hline frequencies, $\mathrm{cm}^{-1}$ & species & mode \\
\hline 2980.2 & $\mathrm{C}_{2} \mathrm{H}_{6}$ & $\mathrm{C}-\mathrm{H}$ stretch \\
\hline 2977.7 & $\mathrm{C}_{2} \mathrm{H}_{5} \mathrm{ZnH}$ & $\mathrm{CH}_{2}$ sym stretch \\
\hline 2974.0 & $\mathrm{C}_{2} \mathrm{H}_{5} \mathrm{ZnH}$ & $\mathrm{CH}_{3}$ sym stretch \\
\hline 2960.2 & $\mathrm{C}_{2} \mathrm{H}_{5} \mathrm{ZnH}$ & $\mathrm{CH}_{3}$ sym stretch \\
\hline 2979.4, 2950.0, 2891.8 & $\mathrm{C}_{2} \mathrm{H}_{6}$ & $v_{7}, v_{5}, v_{8}+v_{11}$ \\
\hline 1888.6 & $\mathrm{C}_{2} \mathrm{H}_{4}$ & $v_{7}+v_{8}$ \\
\hline 1881.3, 1878.7, 1869.3, 1852.1 & $\mathrm{C}_{2} \mathrm{H}_{5} \mathrm{ZnH}$ & $\mathrm{Zn}-\mathrm{H}$ stretch \\
\hline 1870.8 & $\mathrm{ZnH}_{2}$ & $\mathrm{Zn}-\mathrm{H}$ stretch \\
\hline 1849.7 & $\mathrm{H}_{2} \cdots \mathrm{ZnH}_{2}$ & $\mathrm{Zn}-\mathrm{H}$ stretch \\
\hline 1841.9 & $\mathrm{X} \cdots \mathrm{ZnH}_{2}$ & $\mathrm{Zn}-\mathrm{H}$ stretch \\
\hline 1466.1 & $\mathrm{C}_{2} \mathrm{H}_{6}$ & $v_{8}$ \\
\hline 1465.4 & $\mathrm{C}_{2} \mathrm{H}_{5} \mathrm{ZnH}$ & $\mathrm{CH}_{3}$ asym def \\
\hline 1445.3 & DMZ $\cdots \mathrm{C}_{2} \mathrm{H}_{4}$ & $v_{12} \mathrm{C}_{2} \mathrm{H}_{4}$ \\
\hline $1440.5,1437.7$ & $\mathrm{C}_{2} \mathrm{H}_{4}$ & $v_{12}$ \\
\hline 1436.9 & $\mathrm{C}_{2} \mathrm{H}_{5} \mathrm{ZnH}$ & $\mathrm{CH}_{2}$ bend \\
\hline 1378.0 & $\mathrm{C}_{2} \mathrm{H}_{5} \mathrm{ZnH}$ & $\mathrm{CH}_{3}$ sym def \\
\hline $1379.5,1374.8$ & $\mathrm{C}_{2} \mathrm{H}_{6}$ & $\nu_{6}$ \\
\hline $965.8,964.5,960.3$ & $\mathrm{C}_{2} \mathrm{H}_{5} \mathrm{ZnH}$ & $\mathrm{C}-\mathrm{C}$ stretch \\
\hline 956.4 & DMZ $\cdots \mathrm{C}_{2} \mathrm{H}_{4}$ & $v_{7} \mathrm{C}_{2} \mathrm{H}_{4}$ \\
\hline 947.6 & $\mathrm{C}_{2} \mathrm{H}_{4}$ & $v_{7}$ \\
\hline \multicolumn{3}{|l|}{946.6} \\
\hline $829.3,827.2$ & $\mathrm{C}_{2} \mathrm{H}_{5} \mathrm{ZnH}$ & $\mathrm{CH}_{2}$ wag \\
\hline $830.5,822.4,820.4,818.2$ & $\mathrm{C}_{2} \mathrm{H}_{6}$ & $v_{9}$ \\
\hline \multicolumn{3}{|l|}{817.0} \\
\hline \multicolumn{3}{|l|}{737.5} \\
\hline 736.8 & $\mathrm{C}_{2} \mathrm{H}_{2}$ & $v_{5}$ \\
\hline 634.4 & $\mathrm{X} \cdots \mathrm{DMZ}$ & $\mathrm{Zn}-\mathrm{C}$ asym str \\
\hline 628.3 & $\mathrm{ZnH}_{2}$ & bend \\
\hline $599.9,601.5$ & $\mathrm{H}_{2} \cdots \mathrm{ZnH}_{2}$ & bend \\
\hline 579.6 & $\mathrm{X} \cdots \mathrm{ZnH}_{2}$ & bend \\
\hline \multicolumn{3}{|l|}{$608.4,550.7$} \\
\hline 545.8 & $\mathrm{C}_{2} \mathrm{H}_{5} \mathrm{ZnH}$ & C-Zn stretch \\
\hline
\end{tabular}

$\mathrm{ZnH}$ is also in accordance with the data of Mink and Goggin ${ }^{9}$ on ethylmercury halides. The broad feature centered at 635 $\mathrm{cm}^{-1}$ displayed a slight reduction in intensity and splittings at 628.3 and $634.4 \mathrm{~cm}^{-1}$ as depicted in the middle panel of Figure 6. The band centered at $628.3 \mathrm{~cm}^{-1}$ is assigned to the bend of zinc dihydride. The corresponding high-frequency $\mathrm{Zn}-\mathrm{H}$ stretch mode of $\mathrm{ZnH}_{2}$ is observed at $1870.8 \mathrm{~cm}^{-1}$, in agreement with the earlier $\mathrm{Zn}+\mathrm{H}_{2}$ study of Greene et al. ${ }^{10}$ which reported bands at 630.5 and $1870.2 \mathrm{~cm}^{-1}$. The bands at 579.6 and 599.9 $\mathrm{cm}^{-1}$ are assigned to $\mathrm{ZnH}_{2}$ but are perturbed by a neighboring species, namely, $\mathrm{H}_{2}$ for the latter. Their corresponding $\mathrm{Zn}-\mathrm{H}$ stretches are located at 1841.9 and $1849.7 \mathrm{~cm}^{-1}$ as depicted in the middle panel of Figure 4. The remaining unidentified band in the $675-625 \mathrm{~cm}^{-1}$ region occurs at $634.4 \mathrm{~cm}^{-1}$ and is assigned to the $\mathrm{Zn}-\mathrm{C}$ asymmetric stretch of $\mathrm{DMZ}$ perturbed by a neighbor which is shifted to the blue of the parent DMZ absorption at $619.7 \mathrm{~cm}^{-1}$ of the ${ }^{64} \mathrm{Zn}$ isotopomer. Upon close examination, this absorption revealed a 3-fold splitting having intensities of 5:3:2 associated with the relative abundances of the naturally occurring isotopes of atomic zinc. The magnitudes of the splitting between the isotopic components are 2.01 and $1.57 \mathrm{~cm}^{-1}$, which are smaller than those of the unperturbed parent DMZ. Because of the changes occurring in the very strong $v_{7}$ mode of the precursor DMZ molecule at $617.5 \mathrm{~cm}^{-1}$ upon annealing, the present study does not allow an examination for the presence of isolated methyl radical located in this region by Milligan and Jacox. ${ }^{11}$

Ethylene perturbed by hydrogen and DMZ in the argon matrix were proposed as candidates for assignments of the few remaining unidentified weak bands. Spectra recorded for $\mathrm{Ar}$ samples composed of equal mixtures of $\mathrm{C}_{2} \mathrm{H}_{4}$ and $\mathrm{H}_{2}$, made up to a final guest/host dilution ratio of $1 / 300$, were found to be identical to spectra recorded for pure $\mathrm{C}_{2} \mathrm{H}_{4} / \mathrm{Ar}$ and $\mathrm{H}_{2}$-doped $\mathrm{C}_{2} \mathrm{H}_{4} / \mathrm{Ar}$ samples, indicating that no perturbation effects of ethylene were induced by the presence of molecular hydrogen. Likewise, Ar matrices composed of equal amounts of $\mathrm{C}_{2} \mathrm{H}_{4}$ and DMZ were prepared with a final guest/host dilution ratio of $1 / 300$. However, in the spectra of these samples, two new bands were observed at $956.1 \mathrm{~cm}^{-1}$ and a weaker band at $1442.4 \mathrm{~cm}^{-1}$, which agree very well with the bands observed in our photochemical study at 956.4 and $1445.3 \mathrm{~cm}^{-1}$. The band at $956.4 \mathrm{~cm}^{-1}$ is assigned to the $v_{7}$ mode of ethylene perturbed by DMZ. Since both a strong ethylene absorption and a weak DMZ absorption occur at $1437 \mathrm{~cm}^{-1}$, it would appear that the $v_{12}$ mode of ethylene is perturbed by DMZ. The few remaining weak bands which have not been assigned are indicted in Table 2. It would seem likely that these bands are associated with a zinc atom perturbing ethane, ethylene, or DMZ.

\section{Discussion}

A. DMZ Assignments. Assignments of the vibrational transition at $1309.2 \mathrm{~cm}^{-1}$ in the Ar matrix to the $v_{10}+v_{14}$ mode of DMZ were prompted by the gas-phase results of Coats et al. ${ }^{5}$ which indicated that a $\mathrm{CH}_{3}$ deformation of DMZ occurs at $1303.5 \mathrm{~cm}^{-1}$. Currently, this band is incorrectly assigned in the matrix literature methane by Bochmann et al. ${ }^{6}$ to the $v_{4}$ vibrational transition of methane. Confirmation of our assignment is easily established when one compares the pair of spectra shown in Figure 2 of two samples, one containing methane, the other free of it. The vibrational transition marked with an asterisk at $1304.6 \mathrm{~cm}^{-1}$ is clearly due to the methane, while the peak at $1309.2 \mathrm{~cm}^{-1}$ is the $v_{10}+v_{14}$ vibrational transition of DMZ.

B. DMZ Photochemistry. In freshly photolyzed samples, a prominent feature observed at $730.4 \mathrm{~cm}^{-1}$ was observed to disappear completely upon annealing accompanied only by the growth of ethane bands. A band similar to the present 730.4 $\mathrm{cm}^{-1}$ feature was observed by Tan and Pimentel ${ }^{12}$ in matrix reactions of the alkali metals with methyl halides, in which the IR absorptions of a methyl radical were shifted to higher frequencies due to a strong perturbation by a nearby alkali halide molecule. In particular, a methyl radical interacting strongly with lithium halide exhibited very similar absorption at $730 \mathrm{~cm}^{-1}$ which disappeared after sample annealing accompanied by growth of ethane absorptions. ${ }^{13}$ In a parallel photodissociation study, we have conducted ${ }^{14}$ on matrix-isolated DMHg, very similar bands have been observed in this spectral region, showing identical annealing behavior. Based on the similarity of the observations, the prominent feature observed at 730.4 $\mathrm{cm}^{-1}$ in freshly photolyzed DMZ/Ar samples is identified as a methyl radical perturbed by a zinc atom.

From observations made in our UV study, ${ }^{15}$ two photodissociation mechanisms, a concerted loss and a stepwise loss, are proposed to exist in competition for DMZ isolated in solid Ar. The concerted loss mechanism results in permanent dissociation, yielding two methyl radicals separated by a zinc atom, whereas the stepwise loss mechanism will result in geminate recombination of methyl zinc radical and methyl radical to produce DMZ. Because two methyl radicals are separated by a zinc atom, the methyl radicals are strongly perturbed in the divacancy site originally occupied by DMZ molecule. The IR spectra indicate this perturbation by the species absorbing at $730.4 \mathrm{~cm}^{-1}$ identified as a methyl radical in the vicinity of a zinc atom.

Secondary photochemical products, ethylzinc hydride and acetylene, were identified during irradiation. Both species arise as a consequence of a combination of the primary photofragments, two methyl radicals forming both ethane and ethylene 
SCHEME 1:

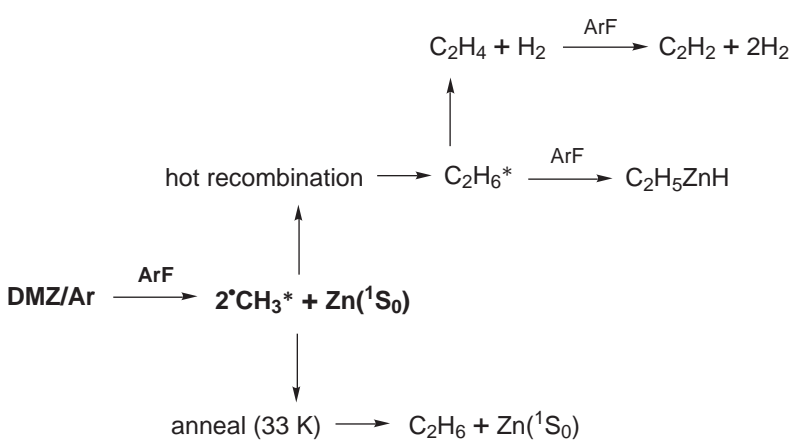

plus hydrogen. It is known that ethylene dissociates in matrices with ArF excitation ${ }^{16}$ forming acetylene. Optical pumping of the other primary product, atomic zinc in the vicinity of ethane, results in ethylzinc hydride. The insertive reaction between $\mathrm{Zn}$ $\left({ }^{1} \mathrm{P}_{1}\right)$ and a $\mathrm{C}-\mathrm{H}$ bond of ethane will be discussed later. Scheme 1 summarizes the competitive photochemical processes of DMZ in solid argon subjected to ArF irradiation and illustrates the mechanism responsible for the production of ethane in both freshly photolyzed and annealed samples. As the photochemical scheme illustrates, the growth of the hydrocarbon species is most pronounced for ethane after annealing due to a recombination of cold methyl radicals, with no additional production of ethylene and acetylene.

Secondary Photochemistry. The identification of ethylzinc hydride as a photochemical product is indicative of a reaction between ethane and zinc. Similar matrix-isolation experiments by Cartland and Pimentel ${ }^{17}$ involving the reaction of ${ }^{3} \mathrm{P}_{1}$ excited state $\mathrm{Hg}, \mathrm{Zn}$, and $\mathrm{Cd}$ with ethyl halide result in the production of an ethylmetal halide in solid krypton via the insertion of the metal atom into the $\mathrm{C}-\mathrm{X}$ bond. More importantly, the reaction of excited $\mathrm{Hg}$ with ethane in $\operatorname{argon}^{8}$ has been investigated, yielding the observation of ethylmercury hydride as a photochemical product. The infrared bands of ethylmercury hydride in solid argon which display similar widths and splittings at frequencies of $1954.8,1946.8$, and $1926.8 \mathrm{~cm}^{-1}$ were assigned to $v(\mathrm{Hg}-\mathrm{H})$ and a $\mathrm{CH}_{2}$ rocking mode at $698.4 \mathrm{~cm}^{-1}$. In this system, insertion of the $\mathrm{C}-\mathrm{H}$ bond proceeded via excitation of the mercury atom via the ${ }^{3} \mathrm{P}_{1}$ excited state and not of the weaker $\mathrm{C}-\mathrm{C}$ bond.

Based on the observations outlined above, it is deduced that a mechanism of insertion is responsible for the reaction between ethane and atomic zinc. However, insertion doesn't proceed via the ${ }^{3} \mathrm{P}_{1}$ excited state of zinc but proceeds via the ${ }^{1} \mathrm{P}_{1}$ excited state because of the ArF laser excitation employed with a output wavelength of $193 \mathrm{~nm}$. Moreover, the ${ }^{1} \mathrm{P}_{1} \leftarrow{ }^{1} \mathrm{~S}_{0}$ transition is reported between 202 and $210.5 \mathrm{~nm},{ }^{18}$ while the spin-forbidden ${ }^{3} \mathrm{P}_{1} \leftarrow{ }^{1} \mathrm{~S}_{0}$ transition is not observed. Although the pumping wavelength of $193 \mathrm{~nm}$ does not coincide with the absorption of matrix-isolated zinc located between 202 and $210.5 \mathrm{~nm}$, it would appear that atomic zinc absorbs sufficiently at $193 \mathrm{~nm}$ to be pumped by the ArF laser and resulting in the production of ethylzinc hydride.

The mechanism of insertion identified via the ${ }^{1} \mathrm{P}_{1}$ excited state of $\mathrm{Zn}$ and the characterization of the photochemical product ethylzinc hydride correlates with observations made in gas-phase reactions of $\mathrm{Zn}\left({ }^{1} \mathrm{P}_{1}\right)$ with the alkane hydrocarbons $\mathrm{CH}_{4}, \mathrm{C}_{2} \mathrm{H}_{6}$, $\mathrm{C}_{3} \mathrm{H}_{8}$, and $\mathrm{C}\left(\mathrm{CH}_{3}\right)_{4}$ by Umemoto et al. ${ }^{19}$ using the laser pumpprobe technique. From an analysis of the rotational state distributions of the nascent $\mathrm{Zn}-\mathrm{H}$ molecule, it was suggested that the gas-phase reaction proceeds via a long-lived insertive intermediate $R-\mathrm{Zn}-\mathrm{H}$, resulting in the production of mainly $\mathrm{ZnH}$ and the fragment alkyl radicals. However, in the matrix, the long-lived intermediate has been stabilized and trapped as evidenced by the observation of the photochemical product $\mathrm{C}_{2} \mathrm{H}_{5}-\mathrm{Zn}-\mathrm{H}$.

The multiplicity of the set of absorption bands in the annealed sample at 1852.1, 1869.3, 1878.7, and $1881.3 \mathrm{~cm}^{-1}$ which were tentatively assigned to the $v(\mathrm{Zn}-\mathrm{H})$ stretching frequency of ethylzinc hydride is a reflection of the isolation of different orientations of the $\mathrm{Zn}-\mathrm{H}$ bond relative to the linear skeletal $\mathrm{C}-\mathrm{C}-\mathrm{Zn}$ chain in the matrix. Multiple weak bands at 956.4, 962.3, 964.5, and $965.8 \mathrm{~cm}^{-1}$ were tentatively assigned to the $\mathrm{C}-\mathrm{C}$ stretch of $\mathrm{C}_{2} \mathrm{H}_{5} \mathrm{ZnH}$. The multiplicity of these bands is also associated with the different configurations of the $\mathrm{Zn}-\mathrm{H}$ bond relative to the linear skeletal $\mathrm{C}-\mathrm{C}-\mathrm{Zn}$ chain $\mathrm{C}_{2} \mathrm{H}_{5} \mathrm{ZnH}$ isolated in the matrix. The four $\mathrm{C}-\mathrm{C}$ bands are narrower than the four $\mathrm{Zn}-\mathrm{H}$ stretch bands located in the $1870-\mathrm{cm}^{-1}$ region, a difference which is attributed to unresolved isotopic splitting of the three dominant naturally occurring isotopes of atomic zinc.

Photodissociation Mechanism of DMZ in Solid Ar. In the gas phase, a stepwise mechanism was identified, ${ }^{20-23}$ as presented in the preceding paper in this issue, to be responsible for the UV photodissociation of DMZ. Thus, absorption of a UV photon by DMZ in both the bent, first excited state and the linear, second excited state produced the monomethylzinc radical in a vibrationally excited state. ${ }^{20}$ Unimolecular dissociation of the vibrationally "hot" methylzinc radical then produces methyl radical and atomic zinc. In the solid, does one expect the above stepwise loss mechanism of the methyl groups of DMZ or is the vibrationally excited methylzinc radical stabilized via energy dissipation to the solid? Since the two dissociation mechanisms ultimately produce atomic zinc and methyl radicals, the key intermediate which allows one to identify the mechanism responsible for the photodissociation of DMZ in solid Ar is the existence of methylzinc. As mentioned earlier, the photochemical fragment methylzinc has not been observed in the present IR study or in our fluorescence study of paper 1 . Thus, one must conclude that permanent production of methylzinc does not occur in the matrix from the dissociation of DMZ.

This pronounced difference to the gas phase is probably arising because of cage recombination. Considering the van der Waals dimensions ${ }^{24}$ of this cylindrical molecule (5.6 $\AA$ length $\times 3.1 \AA$ diameter), DMZ in its ground electronic state can easily be accommodated in a cylindrical $7.5 \times 3.75 \AA$ double-substitutional site in $\mathrm{Ar}$ (usually referred to as a divacancy site) but not in a spherical single-substitutional site having a diameter of only $3.75 \AA$. In sequential dissociation of DMZ, if the first cleaved methyl radical does not manage to exit the divacancy cage occupied by the parent molecule, it will then be obliged to occupy a single-substitutional site but having its sibling fragment, methylzinc radical, ${ }^{25}$ as its next nearestneighbor. Because of the close proximity of these radicals, recombination occurs along a barrierless reaction coordinate regenerating the parent $\mathrm{DMZ}$ molecule. Considering the possibility of this geminate recombination, one cannot rule out cleavage of a single $\mathrm{Zn}-\mathrm{C}$ bond, but it can be stated that, in contrast to the gas phase, a stepwise mechanism does not lead to the production of atomic zinc in the solid. An ultrashort laser pulse experiment would be required to monitor the very fast geminate recombination process proposed herein.

\section{Conclusions}

A reassignment of the vibrational transition at $1309.2 \mathrm{~cm}^{-1}$ to the $v_{10}+v_{14}$ combination mode of DMZ was made, which had in a previous report been confused with the $v_{4}$ mode of methane. The photochemistry of matrix-isolated DMZ mono- 
mer in solid argon was examined using the technique of highresolution FTIR spectroscopy as a sensitive probe of the dissociation event. Of great importance was the characterization of a new type of species: a methyl radical strongly perturbed by a zinc atom, which was crucial for the identification of the dissociation mechanism of DMZ in the solid. Simple hydrocarbons of ethane, ethylene, and acetylene were identified in freshly photolyzed DMZ/Ar samples. It is proposed that the production of ethylene arises from the recombination of hot methyl radicals. Acetylene is produced in turn from the ArF dissociation of ethylene which is known to occur in rare gas matrices. Sample annealing resulted in a more resolved splitting of the absorption features and an enhancement in the production of the ethane bands. The growth of the ethane bands after annealing is considered to be due to a combination of cold methyl radicals and is accompanied by decrease in the 730.4 $\mathrm{cm}^{-1}$ band assigned to the perturbed methyl radical species.

A new species, ethylzinc hydride, was characterized and identified as the result of secondary product of $\mathrm{ArF}$ photolysis. The $\mathrm{CH}_{3} \mathrm{Zn}$ species ${ }^{26}$ whose $\mathrm{Zn}-\mathrm{C}$ stretch is at $445 \mathrm{~cm}^{-1}$ is not observed as a photochemical product nor is the diatomic $\mathrm{Zn}-\mathrm{H}$ at $1493.9 \mathrm{~cm}^{-1}$. No evidence was present to indicate the formation of the inserted product $\mathrm{CH}_{3} \mathrm{ZnH}$ reported by Greene et al. ${ }^{8}$ via the reaction of $\mathrm{Zn}\left({ }^{1} \mathrm{P}_{1}\right)$ with methane, which is simply indicative of the mechanism of photodissociation resulting in the production of atomic zinc separated by two methyl radicals.

Acknowledgment. J.M.C. gratefully acknowledges receipt of a France-Ireland Forbairt/CNRS exchange scheme grant in 1995.

\section{References and Notes}

(1) Gutowsky, H. S. J. Chem. Phys. 1949, 17, 128.

(2) Bunker, A. P. R.; Johns, J. W. C.; McKellar, A. R. W.; diLauro, C. J. Mol. Spectrosc. 1993, 162, 142.

(3) Walsh-Bakke, A. M. J. Mol. Spectrosc. 1972, 413, 1.

(4) Legay-Sommaire, N.; Legay, F. Chem. Phys. Lett. 1993, 207, 123.

(5) Coats, A. M.; McKean, D. C.; Edwards, H. G. M.; Fawcett, V. J. Mol. Struct. 1994, 320, 159.

(6) Bochmann, M.; Chesters, M. A.; Coleman, A. P.; Grinter, R.; Lindler, D. R. Spectrochim. Acta 1992, 48A, 1173.
(7) Difference spectra $A_{D}$ were calculated by using the expression $A_{\mathrm{D}}$ $=\log \left(T_{\mathrm{FD}} / T_{\mathrm{P}}\right)$ in which $T_{\mathrm{FD}}$ and $T_{\mathrm{P}}$ are the recorded transmission spectra of freshly deposited and photolyzed DMZ/Ar samples, respectively.

(8) Greene, T. M.; Andrews, L.; Downs, A. J. J. Am. Chem. Soc. 1995, 117,8180

(9) Mink, J.; Goggin, P. L. J. Organomet. Chem. 1980, 185, 129.

(10) Greene, T. M.; Brown, W.; Andrews, L.; Downs, A. J.; Chertihin, G. V.; Runeberg, N.; Pyykkö, P. J. Phys. Chem. 1995, 99, 7925.

(11) Milligan, D. E.; Jacox, M. E. J. Chem. Phys. 1967, 47, 5146.

(12) Tan, L. Y.; Pimentel, G. C. J. Chem. Phys. 1968, 48, 5202

(13) Andrews, L.; Pimentel, G. C. J. Chem. Phys. 1967, 47, 3637.

(14) Crepin, C.; Legay, N.; Tramer, A.; McCaffrey, J. G. Manuscript in preparation, Oct 1997.

(15) Bracken, V. A.; Gürtler, P.; McCaffrey, J. G. J. Phys. Chem. A 1997, 101, 9854.

(16) Legay, N. Unpublished results, 1996.

(17) Cartland, H. E.; Pimentel, G. C. J. Phys. Chem. 1989, 93, 8021.

(18) Bracken, V. A.; Gürtler, P.; McCaffrey, J. G. J. Chem. Phys. 1997, 107, 5290, 1997, 107, 5300.

(19) Umemoto, H.; Tsunashima, S.; Yokoyama, K.; Misaizu, F.; Fuke, K. J. Chem. Phys. 1994, 101, 4803.

(20) Jackson, R. L. Chem. Phys. Lett. 1990, 174, 53.

(21) Chen, C. J.; Osgood, R. M. J. Chem. Phys. 1984, 81, 327.

(22) Yu, C. F.; Young, F.; Tsukiyama, K.; Bersohn, R.; Preses, J. J. Chem. Phys. 1986, 85, 1382. Penner, A.; Amirav, A.; Bersohn, R. Chem. Phys. Lett. 1991, 176, 147.

(23) Young, P. J.; Gosavi, R. K.; Connor, J.; Strausz, O. P.; Gunning, H. E. J. Chem. Phys. 1973, 18, 5280.

(24) The van der Waals dimensions of DMZ have been estimated as follows: using the $\mathrm{Zn}-\mathrm{C}$ bond length of $\mathrm{DMZ}$ as $1.929 \AA$, a $\mathrm{Zn}-\mathrm{C}-\mathrm{H}$ bond angle of $107.7^{\circ}$, and a $\mathrm{C}-\mathrm{H}$ bond length of $1.09 \AA$, the $\mathrm{H}-\mathrm{H}$ internuclear distance is calculated to be $4.521 \AA$ along the long axis of the molecule, while the $\mathrm{H}-\mathrm{H}$ internuclear diameter perpendicular to this axis is $2.077 \AA$. Adding the Bohr radius of $0.529 \AA$ to represent the minimum van der Waals extent of the $\mathrm{H}$ atoms on the methyl groups, then the length and diameter of DMZ are calculated to be 5.58 and $3.13 \AA$, respectively. The molecular parameters of DMZ taken from: Rao, K. S.; Stoicheff, B. P.; Turner, R. Can. J. Phys. 1960, 38, 1516.

(25) The dimensions of methylzinc have been estimated from the highresolution data of Miller and co-workers [ref 26], also in: Rubino, R.; Williamson, J. M.; Miller, T. A. J. Chem. Phys. 1995, 103, 5964. Using a $\mathrm{Zn}-\mathrm{C}$ bond length of $2.001 \AA$, a $\mathrm{Zn}-\mathrm{C}-\mathrm{H}$ bond angle of $109.21^{\circ}$, and a $\mathrm{C}-\mathrm{H}$ bond length of $1.105 \AA$, the $\mathrm{Zn}-\mathrm{H}$ internuclear distance is calculated to be $2.584 \AA$, while the $\mathrm{H}-\mathrm{H}$ internuclear diameter perpendicular to the $C_{3 v}$ axis is $2.086 \AA$. Adding the Bohr radius of $0.529 \AA$ to represent the minimum van der Waals extent of the $\mathrm{H}$ atoms on the methyl group and $1.5 \AA$ for the van der Waals radius of the $\mathrm{Zn}$ atom, then the diameter and height of this conical molecule are estimated to be 3.145 and $4.4 \AA$, respectively.

(26) Robles, E. S. J.; Ellis, A. M.; Miller, T. A. Chem. Phys. Lett. 1991, 178, 185; Cerny, T. M.; Tan, X. Q.; Williamson, J. M.; Robles, E. S. J. Ellis, A. M.; Miller, T. A. J. Chem. Phys. 1993, 99, 9376. 